\title{
Resistance Training in Breast Cancer Survivors: A Systematic Review of Exercise Programs
}

\author{
Leidy Sofía Montaño-Rojas ${ }^{1, *}$, Ena Monserrat Romero-Pérez ${ }^{2, *}$, Carlos Medina-Pérez ${ }^{3}$, \\ María Mercedes Reguera-García ${ }^{4}$ (D) and José Antonio de Paz ${ }^{5}$ (D) \\ 1 Escuela Normal Superior of Pitalito, 417037 Pitalito, Colombia \\ 2 Department of Sports Science and Physical Activity, University of Sonora, 83000 Hermosillo, Mexico \\ 3 Sciences Health School, University Isabel I, 09003 Burgos, Spain; carlosmedinaper85@gmail.com \\ 4 SALBIS Research Group, Faculty of Health Sciences, Universidad de León, 24071 León, Spain; \\ mercedes.reguera@unileon.es \\ 5 Institute of Biomedicine (IBIOMED), University of Leon, 24071 Leon, Spain; japazf@unileon.es \\ * Correspondence: sofia.montano@normalpitalito.edu.co (L.S.M.-R.); ena.romero@unison.mx (E.M.R.-P.)
}

Received: 7 August 2020; Accepted: 2 September 2020; Published: 7 September 2020

\begin{abstract}
The aim of this study was to identify the characteristics of resistance training (RT) programs for breast cancer survivors (BCS). A systematic review of the literature was performed using PubMed, Medline, Science Direct, the Cochrane Breast Cancer Specialised Register of the Cochrane Library, the Physiotherapy Evidence Database (PEDro), and Scopus, with the aim of identifying all published studies on RT and BCS from 1 January 1990 to 6 December 2019, using the Preferred Reporting Items for Systematic Reviews and Meta-Analyses (PRISMA) guidelines. The risk of bias in the studies was assessed using the revised Cochrane Risk of Bias tool (RoB 2.0). Sixteen trials were included for qualitative analysis. More than half of the trials do not adequately report the characteristics that make up the exercise program. The maximal strength was the most frequently monitored manifestation of strength, evaluated mainly as one-repetition maximum (1RM). Resistance training was performed on strength-training machines, twice a week, using a load between $50 \%$ and $80 \%$ of 1 RM. The trials reported significant improvement in muscle strength, fatigue, pain, quality of life, and minor changes in aerobic capacity.
\end{abstract}

Keywords: breast neoplasms; exercise prescriptions; strength; physical function; quality of life; lymphedema

\section{Introduction}

The health benefits of physical exercise (PE) have been extensively described, highlighting its positive influence on physical, psychological, cognitive, and social condition, as well as its role in disease prevention and treatment, and improvement of quality of life (QoL) [1]. In relation to breast cancer (BC), PE may be an important element in the reduction of risk factors, mortality, and relapse [2-4]. It diminishes the sequelae produced by the treatments against BC, such as the loss of joint mobility and muscle strength, pain, fatigue, anxiety, and depression [5,6]. PE is usually considered a component of the global treatment of disease [7]; it does not cause adverse events and improves the overall condition of breast cancer survivors (BCS) [7-9].

Muscle contraction generates a tension in the muscle, which applied by osteoarticular levers, is able to oppose or overcome an imposed load. This capacity is generically referred to as muscular strength. However, the different outcomes or performances of muscle strength are diverse and are given different names, some of which are used in this review (Table 1). 
Table 1. Definitions of terms used in this review.

\begin{tabular}{cc}
\hline Terms & Definitions \\
\hline Maximum dynamic force & The maximum load you are able to mobilize once (one repetition maximum, 1RM). \\
\hline Muscle power & $\begin{array}{c}\text { The result of the product of the load imposed by the speed at which it moves in a } \\
\text { movement characterized by running in a very short period of time, short and } \\
\text { high-intensity. }\end{array}$ \\
\hline Resistance force (or resistance endurance) & The maximum number of times you are able to mobilize a load. \\
\hline Resistance training & $\begin{array}{c}\text { The generic name used to refer to chronic exercise aimed at maintaining or improving } \\
\text { neuromuscular performance. }\end{array}$ \\
\hline
\end{tabular}

Resistance training (RT) alone is less commonly used than aerobic training (AT) or combined training $(\mathrm{AT}+\mathrm{RT})$, perhaps due to many patients' false belief that exercising with their arms can produce lymphedema [10]. However, the studies carried out so far have ruled out such an idea, and have identified valuable benefits of RT for the musculoskeletal system, joint mobility, fatigue, depression, self-image, and QoL [11-13]. This is why muscle strength exercises are increasingly being included in training programs for breast cancer survivors $[2,14]$. In the literature, a broad range of RT programs developed for BCS can be found, but there is still no consensus on the frequency, intensity, mode, or timing of their prescription $[4,15]$.

In view of such benefits, and in order to make an appropriate prescription for RT, we consider the current knowledge of aspects such as the manifestations of muscle strength that have been used (maximal strength, power, and resistance endurance); evaluation methods (one-repetition maximum, hypothetical maximum force test, use of encoders, body weight, or other methods); frequency of sessions; and intensity of training loads; as well as the results obtained.

The aim of this systematic review was to identify the characteristics of muscle strength evaluation (manifestations of strength, exercises, and muscle groups), the training programs (supervision, resistance type, duration, sets, repetitions, intensity of exercise, sessions per week, and muscle groups or exercises), the secondary objective, the following variable outcomes that were analyzed in each study, the general result obtained, and the safety of the RT in the studies published from 1 January 1990 to 6 December 2019, that have used RT in BCS, before, during, or after treatment.

\section{Methods}

\subsection{Search Strategy}

A systematic review of the literature was performed using PubMed, Medline, Science Direct, the Cochrane Breast Cancer Specialised Register of the Cochrane Library, the Physiotherapy Evidence Database (PEDro), and Scopus, with the aim of identifying all published studies on RT and BCS from 1 January 1990 to 6 December 2019. In addition, potential articles were searched in the reference lists of identified trials and reviews. Two key terms, 'weight training' and 'breast cancer', were used to generate an exhaustive list of keywords. Table 2 shows the full search strategy.

Table 2. Search Terms.

\begin{tabular}{|c|c|}
\hline Search Mode & Advanced \\
\hline Database coverage date & From 1 January 1990 to 6 December 2019 \\
\hline Search term 1 & $\begin{array}{l}\text { OR weight train * OR weight lift * OR resistance train * OR resistance exercise * } \\
\text { OR progressive resisted exercise * OR weight-bearing exercise * OR strength exercise } \\
\text { OR strength train * OR strengthening program * OR exercise training * OR exercise program * } \\
\text { OR physical activity * OR physical exercise * OR rehabilitation * }\end{array}$ \\
\hline Search term 2 & $\begin{array}{c}\text { breast cancer * OR breast neoplasm * OR breast carcinoma * OR breast tumor * } \\
\text { OR mammary neoplasm * OR mammary malignant * OR mammary carcinoma * OR mastectomy * } \\
\text { OR lymph node excision * OR lymphedema * }\end{array}$ \\
\hline Search & Search term 1 AND Search term 2 \\
\hline
\end{tabular}




\subsection{Study Selection}

Two reviewers independently classified and verified the extracted data to present a descriptive summary of the important features of each study. Any disagreement between those reviewers was resolved through discussion with a third reviewer. The titles and abstracts of the remaining articles were examined for eligibility, and those selected were read in full to determine their inclusion according to the pre-defined criteria (Table 3). The excluded studies were those that prescribed a nonconventional RT such as tai chi, Pilates, yoga, Nordic walking, or aquatic exercise. Studies which used different interventions to the RT (e.g., stretching sessions, dietary modification) were excluded. When the sample included patients with more than one type of cancer, the article was included only if the results of RT in BCS were presented independently. The studies that were available only as abstracts were also excluded. We performed a systematic review of the literature using the Preferred Reporting Items for Systematic Reviews and Meta-Analyses (PRISMA) guidelines [16,17].

Table 3. Inclusion criteria.

\begin{tabular}{cc}
\hline Design & Randomized Trials \\
\hline Population & Breast cancer survivors \\
\hline Intervention & Resistance training \\
\hline Outcomes & $\begin{array}{c}\text { Muscle strength evaluation } \\
\text { Resistance training characteristics } \\
\text { Resistance training results }\end{array}$ \\
\hline Comparison & $\begin{array}{c}\text { Control group (without the disease, survivors of breast cancer who developed } \\
\text { other types of training, breast cancer survivors that remained sedentary) } \\
\text { Pre and post-training }\end{array}$ \\
\hline
\end{tabular}

The quality of the selected studies was assessed using the PEDro scale [16,17]. This review includes only randomized trials that applied resistance training (RT) programs in breast cancer survivors (BCS) during or after treatment (surgery, axillary node dissection, radiotherapy, chemotherapy, or hormonal therapy) published from 1 January 1990 to 6 December 2019.

\subsection{Data Extraction and Quality Assessment}

To respond to the main objective of our study, a specific form was developed to extract the relevant information from each of the studies analyzed: the objective, the time of the intervention, the characteristics of the population (e.g., sample size, age, treatment), the study groups, the characteristics of the muscle strength assessment (strength manifestations, exercises, and muscle groups), the RT program (supervision, type of resistance, duration, series, repetitions, exercise intensity, sessions per week, and muscle groups or exercises). To attend to our secondary objective, in each study we analyzed the general result obtained and the safety of the RT.

Two authors independently assessed the risk of bias. In the case of disagreement, the subject was discussed with another author. The risk of bias was assessed using the Cochrane risk-of-bias tool for randomized trials (RoB 2.0) [18,19], which evaluates the risk of bias in five domains; the randomization process, deviations from intended interventions, missing outcome data, measurement of the outcome, and selection of the reported result. A study is considered to be at a "low risk of bias" if all five domains have been judged to be at a low risk of bias. A study is considered to have "some concerns" if it has been judged to raise some concerns in at least one domain. A study is considered to be at a "high risk of bias" overall if it is judged to be at a high risk of bias in at least one domain.

\section{Results}

\subsection{Study Selection}

With the use of the six databases, 133 trials were chosen to be read in full, since they presented information about the developed RT programs. From these 133 studies, 86 corresponded to clinical 
trials, 31 to systematic reviews, and 16 to systematic reviews and meta-analyses. Finally, 41 articles that met the selection criteria were selected (Figure 1). These 41 articles were derived from a total of 16 trials (Table 4) $[7,8,10,20-56]$. The BEATE study $[26,27]$ and the BEST study $[8,28-30]$ were treated as a single trial in the present review because they shared the same training program. The PAL [46-54] study and that of Buchan et al. (2016) [55] also shared the same training program.

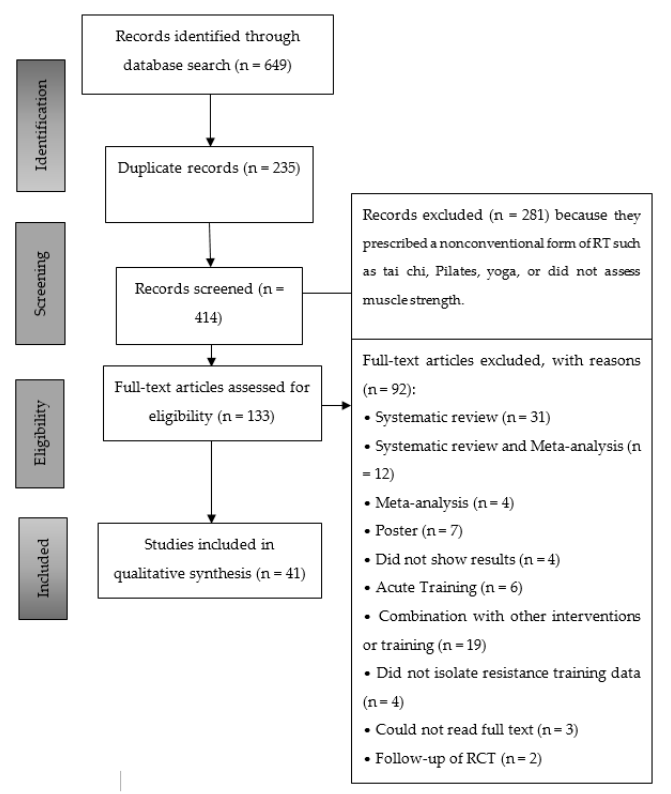

Figure 1. Flow chart for systematic review methodology as per Preferred Reporting Items for Systematic Reviews and Meta-Analyses (PRISMA) guidelines. RT = resistance training; RCT = randomized controlled trial.

Table 4. Studies included in the review.

\begin{tabular}{|c|c|c|}
\hline No. & TRIALS & ARTICLES \\
\hline 1 & START: Supervised Trial of Aerobic Versus & Courneya et al., 2007 [20]-Courneya et al., 2007 [21] \\
\hline & Resistance Training & Courneya et al., 2014 [9]-Adams et al., 2016 [22] \\
\hline 2 & \multicolumn{2}{|c|}{ Schwartz et al., 2007 [23] } \\
\hline 3 & \multicolumn{2}{|c|}{ Schwartz \& Winters-Stone, 2009 [24] } \\
\hline 4 & \multicolumn{2}{|c|}{ Sagen et al., $2009[25]$} \\
\hline \multirow{3}{*}{5} & BEATE: Exercise and relaxation as therapy & Schmidt et al., 2013 [26]-Schmidt et al., 2015 [27] \\
\hline & against fatigue & Potthoff et al., 2013 [28]-Steindorf et al., 2014 [8] \\
\hline & BEST: Exercise and relaxation for breast cancer & Schmidt et al., 2016 [29]-Wiskemann et al., 2017 [30] \\
\hline 6 & \multicolumn{2}{|c|}{ patients during radiotherapy Schmidt et al., 2018 [31] } \\
\hline 7 & Ammitzbøll and colleagues & $\begin{array}{l}\text { Ammitzbøll et al., } 2019 \text { [32]-Ammitzbøll et al., } 2019 \text { [33] } \\
\text { Ammitzbøll et al., } 2019 \text { [34] }\end{array}$ \\
\hline 8 & $\begin{array}{c}\text { WTBS: } \\
\text { Weight Training for Breast Cancer Survivors }\end{array}$ & $\begin{array}{c}\text { Schmitz et al., } 2005 \text { [35]-Ohira et al., } 2006 \text { [36] } \\
\text { Ahmed et al., } 2006 \text { [10] }\end{array}$ \\
\hline 9 & \multicolumn{2}{|c|}{ Twiss et al., 2009 [37] } \\
\hline 10 & \multicolumn{2}{|c|}{ Musanti, 2012 [38] } \\
\hline 11 & \multicolumn{2}{|c|}{ Schmidt et al., 2012 [39] } \\
\hline \multirow[t]{2}{*}{12} & \multicolumn{2}{|c|}{ Simonavice et al., 2014 [40] } \\
\hline & \multicolumn{2}{|c|}{ Hagstrom et al., 2015 [7]-Hagstrom et al., 2016 [41] } \\
\hline 13 & Hagstrom and colleagues & $\begin{array}{c}\text { Hagstrom, A. D., Shorter, K. A., \& Marshall, P. W. } 2019 \\
\text { [42]-Hagstrom, A., \& Denham, J. } 2018 \text { [43] } \\
\text { Hagstrom, A. D., \& Denham, J. } 2018 \text { [44] }\end{array}$ \\
\hline \multirow[t]{4}{*}{14} & \multicolumn{2}{|c|}{ Madzima et al., 2017 [45] } \\
\hline & & Schmitz et al., 2009 [46]-Schmitz et al., 2009 [47] \\
\hline & & Speck et al., 2010 [48]-Schmitz et al., 2010 [49] \\
\hline & PAL: & Hayes et al., 2011 [50]-Brown et al., 2012 [51] \\
\hline \multirow[t]{4}{*}{15} & Physical Activity and Lymphoedema & Winters-Stone et al., 2014 [52] \\
\hline & & Brown \& Schmitz et al., 2015 [53] \\
\hline & & Brown \& Schmitz et al., 2015 [54] \\
\hline & \multicolumn{2}{|c|}{ Buchan et al., 2016 [55] } \\
\hline 16 & Cormie & t al., 2013 [56] \\
\hline
\end{tabular}




\subsection{Characteristics of the Selected Studies}

The scores of the included trials on the PEDro scale are presented in Table 5. Although the first item does not contribute to the total score because it is related to the external validity [15], all the included trials met the external validity item by clarifying the eligibility criteria. All the included trials met the random allocation criteria, reporting between-group differences and point estimates and variability, which contributed to the total score. Only one trial did not report similar groups at baseline [39], five did not use a valid allocation concealment method [23,24,37,40,45], three trials were blinded to the participants $[7,26,40]$, five trials had blinded therapists $[26,31,33,38,56]$, and eight trials had blinded assessors $[7,20,25,31,33,35,38,46]$. Six trials had $>15 \%$ loss to follow-up $[20,25,31,35,38,46]$, and four were not analyzed by intention to treat $[31,35,38,39]$. The risk of bias analysis showed a low risk of bias in five articles, a moderate risk of bias in nine articles, and a high risk of bias in three articles (Figure 2).

The total sample size of the studies included in the review was 1835 participants. The sample sizes of the individual studies varied between 23 and 295 participants. Seven experimental populations utilized samples of more than 100 BCS [20,24,25,28,32,37,46]. None of the articles reported the inclusion of male participants. The mean age ranged from 47 to 64 years old; there were only two experimental populations in which the mean age of participants was below 50 years old $[20,24]$. The BC stage of participants varied between stage 0 and stage III. Stage IV was reported in only one experimental population (Table 6) [26].

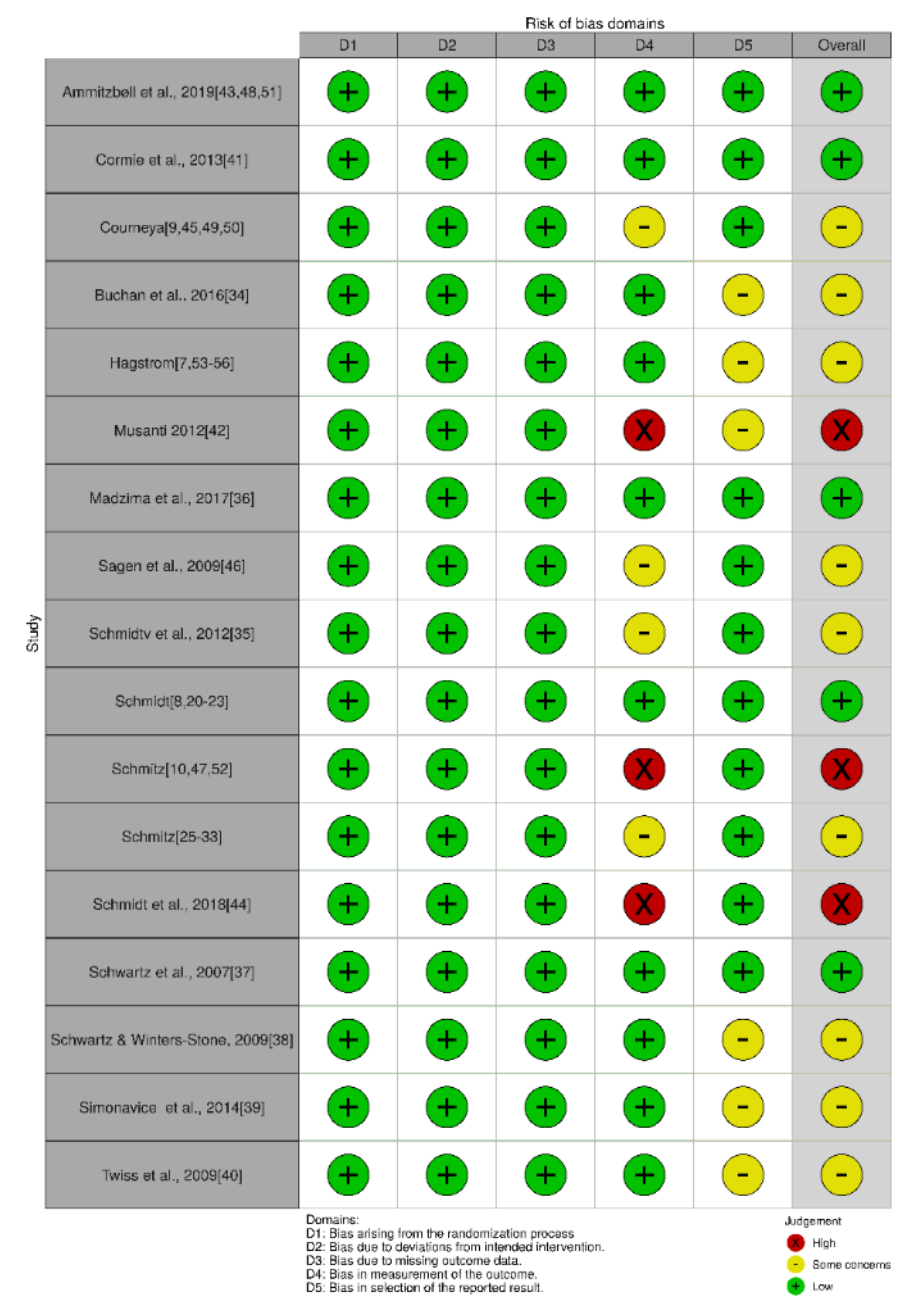

Figure 2. Risk of bias assessment of the randomized trials. 
Table 5. Physiotherapy Evidence Database (PEDro) scores of the included trials $(n=16)$.

\begin{tabular}{|c|c|c|c|c|c|c|c|c|c|c|c|}
\hline Study & $\begin{array}{l}\text { Random } \\
\text { Allocation }\end{array}$ & $\begin{array}{l}\text { Concealed } \\
\text { Allocation }\end{array}$ & $\begin{array}{c}\text { Groups } \\
\text { Similar at } \\
\text { Baseline }\end{array}$ & $\begin{array}{c}\text { Participant } \\
\text { Blinding }\end{array}$ & $\begin{array}{l}\text { Therapist } \\
\text { Blinding }\end{array}$ & $\begin{array}{l}\text { Assessor } \\
\text { Blinding }\end{array}$ & $\begin{array}{c}<15 \% \\
\text { Dropouts }\end{array}$ & $\begin{array}{l}\text { Intention-to-Treat } \\
\text { Analysis }\end{array}$ & $\begin{array}{l}\text { Between-Group } \\
\text { Difference } \\
\text { Reported }\end{array}$ & $\begin{array}{l}\text { Point Estimate and } \\
\text { Variability } \\
\text { Reported }\end{array}$ & Total (0 to 10) \\
\hline $\begin{array}{l}\text { Ammitzbøll et al., } \\
2019 \text { [32-34] }\end{array}$ & $Y$ & $Y$ & $Y$ & $\mathrm{~N}$ & $\mathrm{Y}$ & $\mathrm{Y}$ & $\mathrm{Y}$ & $Y$ & $Y$ & $Y$ & 9 \\
\hline Cormie et al., 2013 [56] & $\mathrm{Y}$ & $\mathrm{Y}$ & $\mathrm{Y}$ & $\mathrm{N}$ & $\mathrm{Y}$ & $\mathrm{N}$ & $\mathrm{Y}$ & $\mathrm{Y}$ & $\mathrm{Y}$ & Y & 8 \\
\hline Courneya $[9,20-22]$ & Y & Y & Y & $\mathrm{N}$ & $\mathrm{N}$ & Y & $\mathrm{N}$ & Y & Y & $\mathrm{Y}$ & 7 \\
\hline Buchan et al., 2016 [55] & Y & Y & Y & $\mathrm{N}$ & $\mathrm{N}$ & $\mathrm{N}$ & Y & Y & Y & Y & 7 \\
\hline Hagstrom $[7,41-44]$ & $\mathrm{Y}$ & $\mathrm{Y}$ & $\mathrm{Y}$ & $\mathrm{Y}$ & $\mathrm{N}$ & $\mathrm{Y}$ & $\mathrm{Y}$ & $\mathrm{Y}$ & $\mathrm{Y}$ & Y & 9 \\
\hline Musanti 2012 [38] & $\mathrm{Y}$ & $\mathrm{Y}$ & Y & $\mathrm{N}$ & $\mathrm{Y}$ & $\mathrm{Y}$ & $\mathrm{N}$ & $\mathrm{N}$ & $\mathrm{Y}$ & $\mathrm{Y}$ & 7 \\
\hline $\begin{array}{l}\text { Madzima et al., } \\
2017 \text { [45] }\end{array}$ & $Y$ & $\mathrm{~N}$ & $Y$ & $\mathrm{~N}$ & $\mathrm{~N}$ & $\mathrm{~N}$ & $Y$ & $Y$ & $Y$ & $Y$ & 6 \\
\hline Sagen et al., 2009 [25] & Y & Y & Y & $\mathrm{N}$ & $\mathrm{N}$ & Y & $\mathrm{N}$ & Y & Y & Y & 7 \\
\hline $\begin{array}{l}\text { Schmidtv et al., } \\
2012 \text { [39] }\end{array}$ & $Y$ & $Y$ & $\mathrm{~N}$ & $\mathrm{~N}$ & $\mathrm{~N}$ & $\mathrm{~N}$ & $Y$ & $\mathrm{~N}$ & $Y$ & $Y$ & 5 \\
\hline Schmidt $[8,26-29]$ & Y & Y & Y & Y & Y & $\mathrm{N}$ & Y & Y & Y & Y & 9 \\
\hline Schmitz $[10,35,36]$ & $\mathrm{Y}$ & $\mathrm{Y}$ & Y & $\mathrm{N}$ & $\mathrm{N}$ & Y & $\mathrm{N}$ & $\mathrm{N}$ & $\mathrm{Y}$ & $\mathrm{Y}$ & 6 \\
\hline Schmitz [46-54] & $\mathrm{Y}$ & $\mathrm{Y}$ & $\mathrm{Y}$ & $\mathrm{N}$ & $\mathrm{N}$ & $\mathrm{Y}$ & $\mathrm{N}$ & $\mathrm{Y}$ & $\mathrm{Y}$ & $\mathrm{Y}$ & 7 \\
\hline $\begin{array}{l}\text { Schmidt et al., } \\
2018 \text { [31] }\end{array}$ & $Y$ & $\mathrm{Y}$ & $Y$ & $\mathrm{~N}$ & $\mathrm{Y}$ & $Y$ & $\mathrm{~N}$ & $\mathrm{~N}$ & $Y$ & $Y$ & 7 \\
\hline $\begin{array}{l}\text { Schwartz et al., } \\
2007[23] \\
\text { Schwartz \& }\end{array}$ & $\mathrm{Y}$ & $\mathrm{N}$ & $\mathrm{Y}$ & $\mathrm{N}$ & $\mathrm{N}$ & $\mathrm{N}$ & $\mathrm{Y}$ & $\mathrm{Y}$ & $Y$ & $Y$ & 6 \\
\hline $\begin{array}{l}\text { Winters-Stone, } \\
2009 \text { [24] }\end{array}$ & $\mathrm{Y}$ & $\mathrm{N}$ & $\mathrm{Y}$ & $\mathrm{N}$ & $\mathrm{N}$ & $\mathrm{N}$ & $\mathrm{Y}$ & $\mathrm{Y}$ & $\mathrm{Y}$ & $\mathrm{Y}$ & 6 \\
\hline $\begin{array}{l}\text { Simonavice et al., } \\
2014 \text { [40] }\end{array}$ & $Y$ & $\mathrm{~N}$ & $Y$ & $Y$ & $\mathrm{~N}$ & $\mathrm{~N}$ & $Y$ & $\mathrm{Y}$ & $Y$ & $\mathrm{Y}$ & 7 \\
\hline Twiss et al., 2009 [37] & Y & $\mathrm{N}$ & $Y$ & $\mathrm{~N}$ & $\mathrm{~N}$ & $\mathrm{~N}$ & $Y$ & $Y$ & $Y$ & $Y$ & 6 \\
\hline
\end{tabular}


Table 6. Characteristics of controlled trials reviewed.

\begin{tabular}{|c|c|c|c|c|c|}
\hline Trial/Author & $\mathbf{N}$ & Age & $\begin{array}{c}\text { Stage of } \\
\text { Cancer }\end{array}$ & Treatment & $\begin{array}{l}\text { Control } \\
\text { Groups }\end{array}$ \\
\hline \multicolumn{6}{|l|}{ During treatment } \\
\hline START [9,20-22] & 242 & 49.2 & I-IIIA & $\mathrm{M}-\mathrm{C}$ & AT-UC \\
\hline Schwartz et al., 2007 [23] & 66 & $50.1 \pm 8.7$ & I-III & $C-R$ & AT-UC \\
\hline Schwartz \& Winters-Stone, 2009 [24] & 101 & $47 \pm 9.4$ & I-III & $\mathrm{C}$ & AT-UC \\
\hline Sagen et al., 2009 [25] & 204 & $55 \pm 10$ & I-III & M/AND-C-R-HT & UC \\
\hline BEATE $[26,27]$ & 95 & $52.7 \pm 10$ & I-IV & $\mathrm{M} / \mathrm{L}-\mathrm{C}$ & PMR \\
\hline BEST $[8,28-30]$ & 155 & $55.8 \pm 9.1$ & $0-\mathrm{III}$ & NC-M/L-R-HT & PMR \\
\hline Buchan et al., 2016 [55] & 40 & 56 & NR & S-C-R-HT & AT \\
\hline Schmidt et al., 2018 [31] & 67 & 54 & NR & S-C & AT-UC \\
\hline Ammitzbøll et al., 2019 [32-34] & 158 & 52 & I-III & S/AND-C-HT & UC \\
\hline \multicolumn{6}{|l|}{ Post-treatment } \\
\hline WTBS $[10,35,36]$ & 79 & $53.3 \pm 8.7$ & I-III & AND-C-R & UC \\
\hline Twiss et al., 2009 [37] & 110 & $58.7 \pm 7.5$ & $0-\mathrm{II}$ & S-C-R & $\mathrm{UC}$ \\
\hline Musanti, 2012 [38] & 42 & 50.5 & I-IIIB & C-R & AT-CT-F \\
\hline Schmidt et al., 2012 [39] & 33 & $58 \pm 8.4$ & I-III & M/L-C-R & CGE \\
\hline Simonavice et al., 2014 [40] & 23 & $64 \pm 5$ & $0-\mathrm{III}$ & S-C-R-HT & $\mathrm{RT}+\mathrm{DP}$ \\
\hline Hagstrom and colleagues $[7,41-44]$ & 39 & $51.9 \pm 8.8$ & I-IIA & S-C-R-HT & UC \\
\hline Cormie et al., 2013 [56] & 62 & $57 \pm 10$ & $0-\mathrm{III}$ & S/AND-C-R-HT & UC \\
\hline PAL $[46-54]$ & 295 & $55.3 \pm 8.5$ & I-III & S/AND-C.HT & UC \\
\hline Madzima et al., 2017 [45] & 33 & $59 \pm 9$ & 0 -III & S-C-R-HT & $\mathrm{RT}+\mathrm{PRO}$ \\
\hline
\end{tabular}

START $=$ Supervised Trial of Aerobic Versus Resistance Training; BEATE $=$ exercise and relaxation as therapy against fatigue; $\mathrm{BEST}=$ exercise and relaxation for breast cancer patients during radiotherapy; $\mathrm{WTBS}=$ Weight Training for Breast Cancer Survivors; PAL = Physical Activity and Lymphoedema; UC = usual care; $\mathrm{R}=$ radiotherapy; $\mathrm{C}=$ chemotherapy $\mathrm{NC}=$ Neoadjuvant chemotherapy; $\mathrm{HT}=$ hormonal therapy; $\mathrm{S}=$ surgery; $\mathrm{M}=$ mastectomy; $\mathrm{L}=$ lumpectomy; $\mathrm{AND}=$ axillary node dissection; $\mathrm{AT}=$ aerobic training; $\mathrm{PMR}=$ Progressive muscle relaxation; $\mathrm{CGE}=$ conventional gymnastics exercise; $\mathrm{F}=$ Flexibility; $\mathrm{CT}=$ combined training; $\mathrm{RT}+\mathrm{DP}=$ resistance training + dried plum; $\mathrm{RT}+\mathrm{PRO}=$ resistance training + protein supplementation.

The most common aim of the selected articles was to identify the effects of RT on QoL (36.3\%) [7-9,20,27,33,36,38,39,48,54-56], followed by identifying the effects of RT on body composition (26.6\%) $[20,22-25,35,40,52,53]$, and on lymphedema (26.6\%) $[10,20,25,32,35,47,49,50,55,56]$. None of the trials investigated a possible preventive role of RT on the development of BC. In the trials in this review, there were two to three study groups that included only BCS, and none of the trials established a comparison with a BC-free population. Of the selected studies, $37.5 \%$ compared trained groups with groups that did not follow any training protocol and that continued their regular care $[7,25,32,37,46,56]$. Another $43.7 \%$ used more than one group including a different activity (AT, RT + supplement, relaxation, or usual care) and compared the results with those of RT [20,23,24,31,38,40,45]. Only one of the articles represented a study comparing different load intensities (high and low) [56].

\subsection{Manifestations of Muscle Strength and Evaluation Methods}

Maximal strength was evaluated in all the trials. The evaluation method and tested limbs were unspecified in one of the 16 trials [25]. The test was performed on the upper and lower extremity, except for one study that evaluated the muscle strength of the upper body (UB) using resistance-endurance [7]. Three trials evaluated resistance-endurance, two of them measured it in the UB $[7,38]$ and one in the lower body (LB) and UB [56].

The most commonly adopted methods of evaluating maximal strength were the one-repetition maximum (1RM), the multiple repetition test (MRT), and the hypothetical maximum force test (h1RM). Eight trials used 1RM to prescribe the RT [7,23,24,35,40,45,54,56], four used the MRT (4RM-8RM) [20,32,38,55], three used the h1RM [26,31,39], two used maximal grip strength [32,56], and one trial did not report any evaluation method [25]. Some studies mentioned the muscle group that was evaluated [26,37] and others specified the type of movement or exercise used $[20,23,24,35,38-40,55]$. Six exercises were used to test the muscle strength of the UB. The most commonly used exercises were the bench/chest press $[7,20,31,35,38-40,45-47,56]$ and the seated 
row $[23,24,38,56]$. The most common exercise to evaluate the muscle strength of the LB was the knee extension $[7,20,23,24,26,31,35,37-40,45,46,56]$. The evaluation methods mentioned were used during and after BC treatment (Table 7).

\subsection{Exercise Prescription}

More than half of the trials developed a supervised training program $[7,20,25,26,31,39,40,45,56]$. The duration of the training programs varied between 12 and 96 weeks, with 12 weeks being the most frequent value $[7,26,31,38,55,56]$. Only one trial did not mention the exact duration of the program, because it depended on the duration of chemotherapy [20]. The frequency ranged from one to four times per week, with two sessions being the most frequent interval $[26,31,32,35,37,40,45,46,56]$. Each session lasted between 20 and $90 \mathrm{~min}$, with $60 \mathrm{~min}$ being the most frequent duration $[7,26,32,35,56]$. Six trials did not mention the duration of the training session $[20,23,38-40,45]$.

Regarding the intensity of the RT of the UB, this variable was not specified in four trials $[23,24,35,37]$; those trials utilized a level of intensity based on the participants' tolerance. In the other trials, variable intensity was employed, with moderate intensity being the most frequent. Low intensity, defined as lower than $50 \%$ of $1 \mathrm{RM}$ or equal to $20-25 \mathrm{RM}$, was used in three trials [25,32,47]. Eleven trials utilized a moderate intensity, between $50 \%$ and $80 \%$ of $1 \mathrm{RM}$ or equal to $8-19 \mathrm{RM}[7,20,26,31,32,35,39,40,45,46,56]$. Five trials used a high intensity, greater than $80 \%$ of $1 R M$ or equal to $5-7$ RM $[20,30,35,46,56]$. One trial used the rated perceived exertion (RPE) scale [38]. The number of sets varied between one and four, but most trials (over $80 \%$ ) used two or three sets per exercise $[7,20,23,24,26,32,35,37,39,40,45,46,56]$. One trial did not report the number of sets [25]. The number of repetitions varied between 8 and 20; 50\% used 8-12 repetitions (Table 8) $[7,20,23,26,35,37,39,40]$. The type of resistance used included strength-training machines $[7,26,31,35,37,39,40,45,46]$, resistance bands $[23,24,38]$, dumbbells, and self-loading $[7,24,32,35,37,46]$. In three studies, the type of resistance used was not mentioned (Table 9) $[20,25,56]$. Nine trials focused on the training of the upper and lower limbs $[20,23,24,27$, $31,35,45,46,56]$. Two trials made no mention of the trained muscular group [25,32]. The other trials aimed to develop muscle strength in the upper and lower limbs and trunk [7,35,37-40]. The most used exercise was the seated row $[7,20,24,26,38-40,45,46,56]$, and the chest press $[7,20,31,35,38-40,45$, $46,56]$. The most common exercise of the LB was the leg press $[7,20,24,26,37-40,45,46,56]$ and the leg extension $[7,20,23,26,31,37,40,45,46,56]$. 
Table 7. Manifestations, methods and muscular groups evaluated.

\begin{tabular}{|c|c|c|c|c|}
\hline \multirow{2}{*}{ Manifestation of Muscle Strength } & \multicolumn{2}{|c|}{ Evaluation Method } & \multicolumn{2}{|c|}{ Movements/Muscular Groups } \\
\hline & UB & LB & UB & LB \\
\hline \multicolumn{5}{|c|}{ During Treatment } \\
\hline Maximal strength & $\begin{array}{c}\text { NR [25] } \\
\text { 1RM [23,24] } \\
\text { MRT (4-8 RM) [9,20-22,3 } \\
\text { h1RM - Brzycki-Method } \\
\text { Maximal grip strength [32-34] } \\
\text { Isometric strength protocol [32-34] }\end{array}$ & $\begin{array}{ll} & \\
\\
32-34,55] \\
{[8,26-31]} \\
& \\
& - \\
& -\end{array}$ & $\begin{array}{c}\text { Chest press [9,20,21,31,55] } \\
\text { Seated row [23,24] } \\
\text { Shoulder press [23,24,31] } \\
\text { Shoulder rotators [8,26-29] } \\
\text { Upper arm curl and extensors [31] } \\
\text { Latissimus pull down - Sit-ups [31] } \\
\text { Shoulder abductors, adductors, } \\
\text { flexors, and extensors [32-34] } \\
\text { Elbow flexion and extension [32-34] }\end{array}$ & $\begin{array}{c}\text { Leg extension }[9,20,21,23,24,31] \\
\text { Knee extensors }[8,26-29] \\
\text { Knee flexors }[8,26-29] \\
\text { Leg curl }[31] \\
\text { Squat }[31] \\
\text { Rowing [31] } \\
\text { Leg press [32-34] }\end{array}$ \\
\hline \multicolumn{5}{|c|}{ Post-treatment } \\
\hline \multirow[b]{2}{*}{ Maximal strength } & $\begin{array}{l}\text { 1RM }[10,35,36,40,45-54,56] \\
\text { Maximal grip strength }[56]\end{array}$ & $1 \mathrm{RM}[7,10,35,36,40,41,45-54,56]$ & Chest press $[7,10,35,36,38-41,45-54,56]$ & Leg extension $[10,35,36,38-40,45]$ \\
\hline & $\begin{array}{r}\text { MRT (6 RM) [38] } \\
\text { BVSE [37] } \\
\text { h1RM [39] } \\
\text { Unilateral isometric strength protocol [7,41] }\end{array}$ & 8] & $\begin{array}{l}\text { Seated row }[38,56] \\
\text { Shoulder press [39] } \\
\text { Latissimus pull down [39] } \\
\text { Sit ups }[38,39]\end{array}$ & $\begin{array}{l}\text { Leg press }[7,41,46-54,56] \\
\text { Leg curl [39] } \\
\text { Squat [39] } \\
\text { Rowing [39] }\end{array}$ \\
\hline Strength-Endurance & $\begin{array}{c}\text { Curl-up test [38] } \\
\text { YMCA Bench Press Endurance Test [38] } \\
\text { Repetition maximum test [56] }\end{array}$ & $\begin{array}{l}- \\
- \\
-\end{array}$ & $\begin{array}{c}\text { Upper arm curl and extensors [39] } \\
\text { Wrist [37] } \\
\text { Handgrip Strength [56] }\end{array}$ & $\begin{array}{c}\text { Hip [37] } \\
\text { Knee extensors [37] } \\
\text { Knee flexor [37] }\end{array}$ \\
\hline
\end{tabular}

$1 \mathrm{RM}=$ one repetition maximum; MRT = multiple repetitions tests; $\mathrm{h} 1 \mathrm{RM}=$ hypothetical maximum force test; $\mathrm{BVSE}=$ Biodex velocity spectrum evaluation; $\mathrm{UB}=$ upper body; LB = lower body; NR = Not reported. 
Table 8. Main characteristics of Exercise Prescription.

\begin{tabular}{|c|c|c|c|c|c|c|}
\hline Trial Duration (Wk.) & Exercise Intensity & Increment & Sets & Repetitions & Sessions/Wk. & Session Duration/Min \\
\hline $\begin{array}{c}12 \\
{[7,8,26-29,31,38,41,45,55,56]}\end{array}$ & NR $[10,23,24,35-37]$ & NR $[7,8,24,26-29,41]$ & NR [25] & $8-10[10,23,35,36]$ & 1 [39] & NR $[9,20,21,23,38-40,45]$ \\
\hline $17[9,20,21]$ & $\begin{array}{c}<50 \% 1 \mathrm{RM} \text { [32-34] } \\
\text { UB: 1-pound weights [46-54] } \\
0.5 \mathrm{~kg} \text {. [25] }\end{array}$ & $\begin{aligned} 10 \% & \rightarrow>12 \text { reps/set }[9,20,21,40] \\
5 \%-10 \% & \rightarrow 2 \text { Sess. }[56]\end{aligned}$ & $1[10,31,35,36,38,56]$ & $\begin{array}{c}8-12[7-9,20,21,26-29,37, \\
39-41]\end{array}$ & $\begin{array}{c}2[8,10,26-29,31-37,40,45- \\
56]\end{array}$ & $20-30$ [24] \\
\hline $20-30[10,23,25,32-36,39,40]$ & $\begin{array}{c}50 \%-80 \% 1 \mathrm{RM} \\
{[7-9,20,21,26-29,31,39-41,45,56]}\end{array}$ & $\begin{array}{l}\text { Modifying starting grip position [23] } \\
\text { Decreasing 5RM x module [32-34] }\end{array}$ & $\begin{array}{c}2[9,10,20,21,23,24,35-37, \\
39,40,46-56]\end{array}$ & $10-12[10,35,36,38,45-55]$ & $3[7,9,20,21,38,41]$ & $>30-45[37]$ \\
\hline $48[10,24,35,36,46-54]$ & $>85 \%$ 1RM [10,35,36,46-55] & $\begin{array}{c}\text { Tolerance }[10,25,35-37,39] \\
\operatorname{RPE}=\leq 3[31,38]\end{array}$ & $\begin{array}{c}3[7,8,10,24,26-29,32-36 \\
41,45-56]\end{array}$ & $11-18 / 20[24,25,31-34]$ & $4[23,24]$ & $50-60[8,10,26-29,35,36]$ \\
\hline $96[37]$ & RPE of 3-5 [38] & UB $=1 / 2$ pound $\rightarrow 2$ Sess. $[46-55]$ & $4[56]$ & $\begin{array}{c}20-15 \text { RM } \\
10-6 \text { RM [56] }\end{array}$ & & $>60-90[46-54]$ \\
\hline
\end{tabular}


Table 9. Muscular Groups Exercised.

\begin{tabular}{|c|c|c|c|}
\hline \multirow[t]{2}{*}{ Supervised Training } & \multirow[t]{2}{*}{ Resistance } & \multicolumn{2}{|c|}{ Movements/Muscular Groups } \\
\hline & & UB & LB \\
\hline YES $[7-9,20,21,25-29,31,39-41,45,56]$ & NR $[9,20-22,25,56]$ & Chest press $[7,9,10,20,21,31,35,36,38-41,45-56]$ & $\begin{array}{c}\text { Leg extension } \\
{[7-9,20,21,23,26-29,31,37,40,41,45-56]}\end{array}$ \\
\hline NO $[23,24,38]$ & Bands $[23,24,38]$ & Seated row $[7-9,20,21,24,26-29,38-41,45-56]$ & Leg press $[7-9,20,21,24,26-29,37-41,45-56]$ \\
\hline PP $[10,32-37,46-55]$ & BW-Dumbbells [7,10,24,32-37,41,46-55] & Shoulder press $[23,24,31,38,39,45,56]$ & Leg curl $[7-9,20,21,26-29,31,37,40,41,45-55]$ \\
\hline- & Machines $[7,8,10,26-31,35-37,39-41,45-55]$ & Lateral, front, and up raise shoulder [46-56] & Squat $[31,38,39,56]$ \\
\hline - & - & Latissimus pull down $[7,8,26-29,31,37-39,41,56]$ & Calf raises $[9,20,21,37]$ \\
\hline - & - & Triceps extension $[9,20,21,31,37-40,56]$ & Lunge $[37,56]$ \\
\hline - & - & Triceps pushdown $[40,45-54]$ & Hip flexion [37-39] \\
\hline - & - & Bicep curl $[9,20,21,31,37-40,45-56]$ & Hip extension [37-39] \\
\hline - & - & Wrist curl $[37,56]$ & Lower back hyperextension $[7,40,41,45]$ \\
\hline - & - & One-arm row-barbell bent $[7,41,46-55]$ & Buttocks, thighs, and legs $[10,35,36]$ \\
\hline - & - & Butterfly and butterfly reverse $[8,26-29]$ & Rowing $[31]$ \\
\hline - & - & Upward row-Push-ups/push-ups on knees-Side hip raise [37] & NR $[25,32-34]$ \\
\hline - & - & Sit-ups $[7,31,37-41,45]$ & - \\
\hline - & - & Prone hold [7,41] Seated [23] & - \\
\hline - & - & Ball-gripping-Wrist extension [37] & - \\
\hline - & - & Shoulder flexion; shoulder extension [38] & - \\
\hline - & - & Back extension $[7,37,41,46-55]$ back $[10,35,36]$ & - \\
\hline - & - & Shoulder rotators $[8,26-29]$ shoulders $[10,35,36]$ & - \\
\hline- & - & NR $[25,32-34]$ & - \\
\hline - & - & - & - \\
\hline
\end{tabular}

$\mathrm{PP}=$ part of the program; $\mathrm{NR}$ = not reported; $\mathrm{BW}$ = body weight; $\mathrm{UB}=$ upper body strength; $\mathrm{LB}=$ lower body strength. 


\subsection{Results and Safety of Resistance Training}

Eight trials evaluated aspects of the body composition, six trials reported improvements [20,23,35, $40,46,51,53]$, and two did not find changes in any of the evaluated variables (muscle mass, mineral bone density, fat mass, or body mass index). Twelve trials reported significant improvement in muscle strength $[7,20,23,24,26,35,37,38,40,45,46,56]$, whereas the others did not provide information $[20,25,31$, $32,39]$. Six trials assessed aerobic capacity, with two reporting significant improvement $[24,55]$ and two reporting minor changes $[20,23,38,39]$. There was a significant improvement in aspects related to QoL $[7,20,26,33,35,39,46,56]$, self-perception [20,38,46], balance [37], joint range of motion [56], and fatigue and pain $[7,20,25,26,38]$ in all evaluated cases $[7,20,26,33,35,39,46,56]$. Only one of the three trials evaluating depression reported a significant improvement [38]. None of the trials reported changes in the participants' physical activity habits after the conclusion of the training program. Regardless of when the resistance training took place (during/after the BC treatment), QoL, self-perception, pain, fatigue, body composition, and muscle strength showed significant improvements. Most studies did not report changes in aerobic capacity or lymphedema during or after treatment (Table 10).

Table 10. Results and safety of resistance training.

\begin{tabular}{|c|c|}
\hline Result & Training Safety \\
\hline \multicolumn{2}{|c|}{ During Treatment } \\
\hline$\uparrow$ Muscle strength $[8,9,20,21,23,24,26-30,55]$ & No adverse events $[8,9,20-22,24-30,32-34,55]$ \\
\hline$\uparrow$ Aerobic capacity $[24,55]$ & NR $[23,31]$ \\
\hline$\leftrightarrow$ Aerobic capacity $[8,9,20,21,26-29]$ & - \\
\hline$(\uparrow)$ Aerobic capacity [23] & - \\
\hline$\downarrow$ Fatigue $[8,9,20,21,26-29]$ & - \\
\hline$\leftrightarrow$ Bodyweight [24] & - \\
\hline$\leftrightarrow$ Body composition [24] & - \\
\hline Attenuates the decrease in BMD [23] & - \\
\hline$\uparrow \operatorname{LBM}[9,20,21]$ & - \\
\hline$\leftrightarrow$ Upper Limbs Volume $[9,20,21,25,32-34,55]$ & - \\
\hline$\downarrow$ Sarcopenia and Dynapenia [22] & - \\
\hline$\uparrow$ QoL $[8,9,20-22,26-29,33,55]$ & - \\
\hline$\uparrow$ Self-perceptions $[9,20,21]$ & - \\
\hline$\downarrow$ Anxiety $[9,20,21]$ & - \\
\hline$\leftrightarrow$ Depression [8,26-29] & - \\
\hline$\downarrow$ Pain $[8,25-29]$ & - \\
\hline Stronger effects on DFS, OS, DDFS, RFI $[9,20,21]$ & - \\
\hline ( $\uparrow$ Cognitive performance $[8,26-29]$ & - \\
\hline$\downarrow$ IL-6, IL-6/IL-1ra [8,26-29] & - \\
\hline Not suppress cellular immunity [31] & - \\
\hline \multicolumn{2}{|c|}{ Post Treatment } \\
\hline 个Muscle strength $[7,10,35-38,40-42,45-54,56]$ & $\leftrightarrow$ Incidence of fractures or falls $[37,46-54]$ \\
\hline$\uparrow$ Muscle endurance [56] & NR $[7,38-41]$ \\
\hline$\leftrightarrow$ EMG [42] & No adverse events $[45-54,56]$ \\
\hline$(\uparrow)$ Aerobic capacity [39] & $\downarrow$ Number and severity of symptoms [46-54] \\
\hline$\downarrow$ Fatigue $[7,38,41]$ & 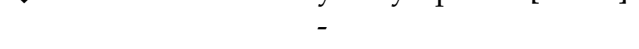 \\
\hline$\uparrow$ Perceived exertion [39] & - \\
\hline$(\uparrow)$ ROM [38] & - \\
\hline$\uparrow \operatorname{ROM}[56]$ & - \\
\hline$\leftrightarrow$ BMI $[10,35,36,40,46-54]$ & - \\
\hline$(\downarrow)$ BMI [39] & - \\
\hline$\leftrightarrow$ Body weight $[10,35,36,46-54]$ & - \\
\hline$\leftrightarrow$ Body composition $[7,10,35,36,41,46-54]$ & - \\
\hline$\downarrow$ Body fat $[45-54]$ & - \\
\hline$\leftrightarrow$ Bone formation $[40,46-54]$ & - \\
\hline
\end{tabular}


Table 10. Cont.

\begin{tabular}{cc}
\hline \multicolumn{1}{c}{ Result } & Training Safety \\
\hline $\begin{array}{c}\downarrow \text { Pone resorption [40] Treatment } \\
\uparrow \text { LBM [10,35,36] }\end{array}$ & - \\
\hline $\begin{array}{c}\text { Pttenuates the muscle mass decline [46-54] } \\
\leftrightarrow \text { Circumference [10,35,36,46-54,56] }\end{array}$ & - \\
$\leftrightarrow$ Upper Limbs Volume [46-54] & - \\
$\uparrow$ Balance [37] & - \\
$\uparrow$ QoL [7,10,35,36,39,41,46-54,56] & - \\
$\leftrightarrow$ Depression [10,35,36,38] & - \\
$\downarrow$ Depression [38] & - \\
$\uparrow$ Self-perceptions [38,46-54] & - \\
$\leftrightarrow$ Norman score [46-54] & - \\
$\downarrow$ Deterioration of physical function [46-54] & - \\
$\leftrightarrow$ DASH, BPI, FACT-B+4 or QLQ-BR23 [56] & - \\
$\downarrow$ IGF-II levels [10,35,36] & - \\
$\uparrow$ IGF-1 [45] & - \\
$\downarrow$ TNF- $\alpha$ on their NK cells [7,41] & - \\
$\leftrightarrow$ miRNA [44] & - \\
Positive correlations between strength & - \\
improvements and changes to circulating & - \\
miRNAs [44] & - \\
$\leftrightarrow$ Telomere length [43] &
\end{tabular}

$\mathrm{BMI}=$ body mass index; $\mathrm{BMD}=$ bone mineral density; DXA = dual x-ray absorptiometry; $\mathrm{QoL}=$ quality of life; $\mathrm{LBM}=$ lean body mass; $\mathrm{ROM}=$ range of motion; $\mathrm{EMG}=$ electromyographic; DASH = the disability of the arm, shoulder, and hand questionnaire; BPI = brief pain inventory; $($ FACT-B +4$)=$ functional evaluation of chronic illness therapy breast cancer questionnaire; QLQ-BR23 = quality of life questionnaire module for breast cancer patients; SF-36 = short form questionnaire; VAS = visual analogue scales; PSPP = physical self-perception profile; BIRS = body image and relationships scale; DFS = disease free survival; OS = overall survival; DDFS = distant DFS; RFI = recurrence-free interval; IL-6 = interleukin-6; IL-1Ra = interleukin 1 receptor antagonist; IGF-II = insulin-like growth factor II; IGF-I = insulin-like growth factor I; TNF- $\alpha=$ tumor necrosis factor alpha; NK = natural killer; NKT $=$ natural killer invariant; $\uparrow$ significant increase; $\downarrow$ significant decrease; $\leftrightarrow$ without changes; $(\uparrow)$ no significant increase; $\mathrm{NP}=$ not reported.

According to the reviewed studies, safety was not affected by the physical exercises carried out, the type of resistance used (free weight, resistance bands, dumbbells, strength-training machines), or the load intensity. Eleven trials did not report any adverse effects of RT [7,20,24-26,32,35,37,45,54,56], and the other six studies did not report about training safety $[7,23,31,37-40]$. In relation to the effect of PE on lymphedema in BCS, none of the six trials that evaluated this relation found an increase in lymphedema $[20,25,26,32,35,46,56]$.

Detailed data from the studies are available as supplementary material: Table S1: Characteristics of controlled trials reviewed, Table S2: Outcomes, measuring tools, and main findings, Table S3: Exercise prescription.

\section{Discussion}

Of the 133 publications initially considered, 47 were reviews and meta-analyses with different RT approaches in BCS, which illustrates the interest in unifying and corroborating the effects of this type of training. Nevertheless, it is important to take into account that more than half of the publications found were derived from only 16 trials. This small reference pool reveals the need for more research in this area. Another limitation concerned the samples used in the trials, most of which included fewer than 80 participants; only two of the trials had large sample sizes (242 and 295 BCS, respectively) [20,46]. It is necessary to unify the designs of the interventions with large samples that provide comparable information and more valid conclusions. 
A few of the systematic reviews focused on RT in BCS populations. Most reviews described the general characteristics of the trials, training program, and obtained results in contrast with other types of training, especially with cancer survivors having, or at risk of developing, lymphedema related to BC; however, these descriptions were generic and not explicit enough regarding the resistance evaluation method, exercise intensity, progress, the type of resistance and exercise used during evaluation, and the training program. This lack of detail constitutes a limitation when comparing the results, the possibility of implementing training programs in other contexts, and at the same time, unifying the recommendations related to RT for BCS.

One of the greatest fears of BCS in relation to RT is the worsening of symptoms, or the exacerbation of lymphedema, which constitutes one of the most discussed topics in the selected literature [11,13-15,57] . The results of the studies on RT suggest that if there is control and progression in the training, considering the individuality of the participants, then there will be no increased risk or worsening of the symptoms or severity of lymphedema $[13,15]$, regardless of the evaluation protocol, training program, or timing of intervention (during or after treatment). It can be said that this type of training is safe, and that contrary to the general precept, lymphedema symptoms and exacerbation are not increased by this form of training $[20,25,26,32,35,46,56,57]$.

Training also influences the patients' psychological condition and quality of life during and after cancer treatment [11]. Variables such as body composition and aerobic capacity did not always show significant changes, perhaps due to the intensity, frequency, or type of training used. The effects of RT on muscle strength and joint motion were not often considered as research objectives, despite the fact that they were evaluated in most the trials for the prescription of $\mathrm{PE}$, and they were two of the aspects that were impaired after BC surgery and were related to QoL. In the two studies that evaluated joint motion $[38,56]$, improvement was observed in the range of motion, without any adverse effects, among women who had concluded chemotherapy and radiation therapy. Similarly, muscle strength improved significantly $[7,20,23,24,26,35,37,38,40,45,46,56]$, sometimes exceeding the amount of muscle strength lost after the surgery [14]. Muscle strength is important, in that it reduces musculoskeletal injuries [15]. Apparently, there was a significant gain of muscle strength regardless of the duration of the training program, training intensity (high, low, moderate), or timing of intervention $[20,35,37,40,47,56]$. Some studies mentioned that training during treatment led to better and faster effects on mobility than late interventions; however, further evidence is required. Determining which training regimens are most effective in improving muscle strength, range of motion, conservation of bone structure, and reduction of fat mass could be a potentially interesting research direction. Some studies have reported isolated data, but there is a need for more evidence.

Considering the timing of the development of the training program, it is suggested that RT prior to the administration of $\mathrm{BC}$ treatment would help patients address the damage and alterations caused by the treatment, such as the loss of muscle mass, muscle strength, and mobility, thus also affecting health-related QoL, which was better in people who were physically active before diagnosis than in those who were sedentary [14].

In light of the published studies, professionals who care for the health of breast cancer survivors can inform their patients that RT is safe and can provide important benefits. Although the quality of the description of the RT programs carried out needs to be further improved, there are sufficient studies that can guide professionals in prescribing this type of exercise, ensuring safety in training programs, and providing guidance as to their frequency, load, number of series and repetitions, and methods of carrying them out.

\section{Conclusions}

Most studies used the evaluation of maximal strength to develop training programs, none of the studies performed an evaluation of muscle power, and only three studies evaluated resistance-endurance. 
RT in BCS is typically performed on strength training machines, twice a week, using a load between $50 \%$ and $80 \%$ of $1 \mathrm{RM}$, with sessions of $60 \mathrm{~min}$ and with two or three sets of 8 to 12 repetitions for each muscle group worked.

The measured outcomes of intervention with this type of training mostly focused on the effect on QoL, followed by the effects on lymphedema, fatigue, and body composition.

In view of these studies, it can be emphasized that $\mathrm{RT}$ is safe, that it does not adversely affect the development or worsening of lymphedema, and that it helps improve the QoL of these patients.

RT can be considered an additional treatment with which to supplement adjuvant and rehabilitation therapy for BCS. It is necessary that trials describe with sufficient precision the manifestation of muscle strength studied, the methods for evaluating it, and the method of individualizing the training load, which would allow these studies to be replicated and compared.

Supplementary Materials: The following are available online at http://www.mdpi.com/1660-4601/17/18/6511/s1, Table S1: Characteristics of controlled trials reviewed, Table S2: Outcomes, measuring tools, and main findings, Table S3: Exercise prescription

Author Contributions: Conceptualization, L.S.M.-R., E.M.R.-P. and J.A.d.P.; methodology, L.S.M.-R., M.M.R.-G. and E.M.R.-P.; formal analysis, L.S.M.-P. and C.M.-P.; investigation, L.S.M.-R. and J.A.d.P.; writing-original draft preparation, L.S.M.-R. and E.M.R.-P.; writing—review and editing, L.S.M.-P., C.M.-P., and M.M.R.-G.; supervision, J.A.d.P. All authors have read and agreed to the published version of the manuscript.

Funding: This research received no external funding.

Conflicts of Interest: The authors declare no conflict of interest.

\section{References}

1. Warburton, D.E.R.; Bredin, S.S.D. Health Benefits of Physical Activity: A Strengths-Based Approach. J. Clin. Med. 2019, 8, 2044. [CrossRef]

2. Battaglini, C.L.; Mills, R.C.; Phillips, B.L.; Lee, J.T. Twenty-five years of research on the effects of exercise training in breast cancer survivors: A systematic review of the literature. World J. Clin. Oncol. 2014, 5, 177-190. [CrossRef]

3. Kim, J.; Choi, W.J.; Jeong, S.H. The effects of physical activity on breast cancer survivors after diagnosis. J. Cancer Prev. 2013, 18, 193-200. [CrossRef]

4. Baumann, F.T.; Bloch, W.; Weissen, A.; Brockhaus, M.; Beulertz, J.; Zimmer, P.; Streckmann, F.; Zopf, E.M. Physical Activity in Breast Cancer Patients during Medical Treatment and in the Aftercare-A Review. Breast Care 2013, 8, 330-334. [CrossRef]

5. Mishra, S.I.; Scherer, R.W.; Snyder, C.; Geigle, P.M.; Berlanstein, D.R.; Topaloglu, O. Exercise interventions on health-related quality of life for people with cancer during active treatment. Cochrane Database Syst. Rev. 2012, 8. [CrossRef]

6. Levangie, P.K.; Drouin, J. Magnitude of late effects of breast cancer treatments on shoulder function: A systematic review. Breast Cancer Res. Treat. 2009, 116, 1-15. [CrossRef]

7. Hagstrom, A.D.; Marshall, P.W.M.; Lonsdale, C.; Cheema, B.S.; Fiatarone, M.A.; Green, S. Resistance training improves fatigue and quality of life in previously sedentary breast cancer survivors: A randomised controlled trial. Eur. J. Cancer Care. 2015. [CrossRef]

8. Steindorf, K.; Schmidt, M.E.; Klassen, O.; Ulrich, C.M.; Oelmann, J.; Habermann, N.; Beckhove, P.; Owen, R.; Debus, J.; Wiskemann, J.; et al. Randomized, controlled trial of resistance training in breast cancer patients receiving adjuvant radiotherapy: Results on cancer-related fatigue and quality of life. Ann. Oncol. 2014, 25, 2237-2243. [CrossRef]

9. Courneya, K.S.; Segal, R.J.; McKenzie, D.C.; Dong, H.; Gelmon, K.; Friedenreich, C.M.; Yasui, Y.; Reid, R.D.; Crawford, J.J.; Mackey, J.R. Effects of exercise during adjuvant chemotherapy on breast cancer outcomes. Med. Sci. Sports Exerc. 2014, 46, 1744-1751. [CrossRef]

10. Ahmed, R.L.; Thomas, W.; Yee, D.; Schmitz, K.H. Randomized controlled trial of weight training and lymphedema in breast cancer survivors. J. Clin. Oncol. 2006, 24, 2765-2772. [CrossRef]

11. Cheema, B.; Gaul, C.A.; Lane, K.; Fiatarone Singh, M.A. Progressive resistance training in breast cancer: A systematic review of clinical trials. Breast Cancer Res. Treat. 2008, 109, 9-26. [CrossRef] 
12. Courneya, K.S.; McKenzie, D.C.; Mackey, J.R.; Gelmon, K.; Friedenreich, C.M.; Yasui, Y.; Reid, R.D.; Vallerand, J.R.; Adams, S.C.; Proulx, C.; et al. Subgroup effects in a randomised trial of different types and doses of exercise during breast cancer chemotherapy. Br. J. Cancer. 2014, 111, 1718-1725. [CrossRef]

13. Keilani, M.; Hasenoehrl, T.; Neubauer, M.; Crevenna, R. Resistance exercise and secondary lymphedema in breast cancer survivors-a systematic review. Supportive Care Cancer 2016, 24, 1907-1916. [CrossRef]

14. Cheema, B.S.; Kilbreath, S.L.; Fahey, P.P.; Delaney, G.P.; Atlantis, E. Safety and efficacy of progressive resistance training in breast cancer: A systematic review and meta-analysis. Breast Cancer Res. Treat. 2014, 148, 249-268. [CrossRef] [PubMed]

15. Paramanandam, V.S.; Roberts, D. Weight training is not harmful for women with breast cancer-related lymphoedema: A systematic review. J. Physiother. 2014, 60, 136-143. [CrossRef]

16. Liberati, A.; Altman, D.G.; Tetzlaff, J.; Mulrow, C.; Gøtzsche, P.C.; Ioannidis, J.P.A.; Clarke, M.; Devereaux, P.J.; Kleijnen, J.; Moher, D. The PRISMA statement for reporting systematic reviews and meta-analyses of studies that evaluate healthcare interventions: Explanation and elaboration. J. Clin. Epidemiol. 2009, 62. [CrossRef]

17. Maher, C.G.; Sherrington, C.; Herbert, R.D.; Moseley, A.M.; Elkins, M. Reliability of the PEDro scale for rating quality of randomized controlled trials. Phys. Ther. 2003, 83, 713-721. [CrossRef]

18. Sterne, J.A.C.; Savović, J.; Page, M.; Elbers, R.; Blencowe, N.S.; Boutron, L.; Cates, C.J.; Cheng, H.-Y.; Sorbett, M.S.; Eldridge, S.M.; et al. RoB 2: A revised tool for assessing risk of bias in randomised trials. BMJ 2019, 366. [CrossRef]

19. McGuinness, L.A.; Higgins, J.P.T. Risk-of-bias VISualization (robvis): An R package and Shiny web app for visualizing risk-of-bias assessments. Res. Synth. Methods 2020. [CrossRef]

20. Courneya, K.S.; Segal, R.J.; Mackey, J.R.; Gelmon, K.; Reid, R.D. Effects of aerobic and resistance exercise in breast cancer patients receiving adjuvant chemotherapy: A multicenter randomized controlled trial. J. Clin. Oncol. 2007, 25, 4396-4404. [CrossRef]

21. Courneya, K.S.; Segal, R.J.; Gelmon, K.; Reid, R.D.; Mackey, J.; Friedenreich, C.M.; Proulx, C.; Lane, K.; Ladha, A.B.; Vallance, J.K.; et al. Six-month follow-up of patient-rated outcomes in a randomized controlled trial of exercise training during breast cancer chemotherapy. Cancer Epidemiol. Biomark. Prev. 2007, 16, 2572-2578. [CrossRef] [PubMed]

22. Adams, S.C.; Segal, R.J.; McKenzie, D.C.; Vallerand, J.R.; Morielli, A.R.; Machey, J.R.; Gelmon, K.; Friedenreich, C.M.; Reid, R.D.; Courneya, K.S. Impact of resistance and aerobic exercise on sarcopenia and dynapenia in breast cancer patients receiving adjuvant chemotherapy: A multicenter randomized controlled trial. Breast Cancer Res. Treat. 2016, 158, 497-507. [CrossRef]

23. Schwartz, A.L.; Winters-Stone, K.; Gallucci, B. Exercise effects on bone mineral density in women with breast cancer receiving adjuvant chemotherapy. Oncol. Nurs. Forum 2007, 34, 627-633. [CrossRef]

24. Schwartz, A.L.; Winters-Stone, K. Effects of a 12-month randomized controlled trial of aerobic or resistance exercise during and following cancer treatment in women. Phys. Sportsmed. 2009, 37, 62-67. [CrossRef]

25. Sagen, A.; Karesen, R.; Risberg, M.A. Physical activity for the affected limb and arm lymphedema after breast cancer surgery. A prospective, randomized controlled trial with two years follow-up. Acta Oncol. 2009, 48, 1102-1110. [CrossRef]

26. Schmidt, M.E.; Wiskemann, J.; Krakowski-Roosen, H.; Knicker, A.J.; Habermann, N.; Schneeweiss, A.; Ulrich, C.M.; Steindorf, K. Progressive resistance versus relaxation training for breast cancer patients during adjuvant chemotherapy: Design and rationale of a randomized controlled trial (BEATE study). Contemp. Clin. Trials 2013, 34, 117-125. [CrossRef]

27. Schmidt, M.E.; Wiskemann, J.; Armbrust, P.; Schneeweiss, A.; Ulrich, C.M.; Steindorf, K. Effects of resistance exercise on fatigue and quality of life in breast cancer patients undergoing adjuvant chemotherapy: A randomized controlled trial. Int. J. Cancer 2015, 137, 471-480. [CrossRef]

28. Potthoff, K.; Schmidt, M.E.; Wiskemann, J.; Hof, H.; Klassen, O.; Habermann, N.; Beckhove, P.; Debus, J.; Ulrich, C.M.; Steindorf, K. Randomized controlled trial to evaluate the effects of progressive resistance training compared to progressive muscle relaxation in breast cancer patients undergoing adjuvant radiotherapy: The BEST study. BMC Cancer 2013, 13, 162. [CrossRef]

29. Schmidt, M.E.; Meynkohn, A.; Habermann, N.; Wiskemann, J.; Oelmann, J.; Hof, H.; Wessels, S.; Klassen, O.; Debus, J.; Potthoff, K.; et al. Resistance Exercise and Inflammation in Breast Cancer Patients Undergoing Adjuvant Radiation Therapy: Mediation Analysis From a Randomized, Controlled Intervention Trial. Int. J. Radiat. Oncol. Biol. Phys. 2016, 94, 329-337. [CrossRef] 
30. Wiskemann, J.; Schmidt, M.E.; Klassen, O.; Debus, J.; Ulrich, C.M.; Potthoff, K. Effects of 12-week resistance training during radiotherapy in breast cancer patients. Scand. J. Med. Sci. Sports 2017, 27, 1500-1510. [CrossRef]

31. Schmidt, T.; Jonat, W.; Wesch, D.; Oberg, H.-H.; Adam-Klages, S.; Keller, L.; Röcken, C.; Mundhenke, C. Influence of physical activity on the immune system in breast cancer patients during chemotherapy. J. Cancer Res. Clin. Oncol. 2018, 144, 579-586. [CrossRef]

32. Ammitzboll, G.; Lanng, C.; Kroman, N.; Zerghn, B.; Hyldegaard, O.; Andersen, G.A.; Johansen, C.; Dalton, S.O. Progressive strength training to prevent LYmphoedema in the first year after breast CAncer-The LYCA feasibility study. Acta Oncol. 2017, 56, 360-366. [CrossRef]

33. Ammitzboll, G.; Kristina Kjaer, T.; Johansen, C.; Lanng, C.; Andersen, E.W.; Kroman, N.; Zerahn, B.; Hyldegaard, O.; Bidstrup, P.E.; Dalton, S.O. Effect of progressive resistance training on health-related quality of life in the first year after breast cancer surgery-Results from a randomized controlled trial. Acta Oncol. 2019, 58, 665-672. [CrossRef]

34. Ammitzboll, G.; Johansen, C.; Lanng, C.; Andersen, E.W.; Kroman, N.; Zerhn, B.; Hyldegarrd, O.; Wittenkamp, M.C. Progressive resistance training to prevent arm lymphedema in the first year after breast cancer surgery: Results of a randomized controlled trial. Cancer 2019, 125, 1683-1692. [CrossRef]

35. Schmitz, K.H.; Ahmed, R.L.; Hannan, P.J.; Yee, D. Safety and efficacy of weight training in recent breast cancer survivors to alter body composition, insulin, and insulin-like growth factor axis proteins. Cancer Epidemiol. Biomark. Prev. 2005, 14, 1672-1680. [CrossRef]

36. Ohira, T.; Schmitz, K.H.; Ahmed, R.L.; Yee, D. Effects of weight training on quality of life in recent breast cancer survivors: The Weight Training for Breast Cancer Survivors (WTBS) study. Cancer 2006, 106, 2076-2083. [CrossRef]

37. Twiss, J.J.; Waltman, N.L.; Berg, K.; Ott, C.d.; Gross, G.J.; Lindsey, A.M. An exercise intervention for breast cancer survivors with bone loss. J. Nurs. Scholarsh. 2009, 41, 20-27. [CrossRef]

38. Musanti, R. A study of exercise modality and physical self-esteem in breast cancer survivors. Med. Sci. Sports Exerc. 2012, 44, 352-361. [CrossRef]

39. Schmidt, T.; Weisser, B.; Jonat, W.; Baumann, F.T.; Mundhenke, H. Gentle strength training in rehabilitation of breast cancer patients compared to conventional therapy. Anticancer Res. 2012, 32, 3229-3233.

40. Simonavice, E.; Liu, P.Y.; Ilich, J.Z.; Kim, J.-S.; Arjmandi, B.; Panton, L.B. The effects of a 6-month resistance training and dried plum consumption intervention on strength; body composition; blood markers of bone turnover; and inflammation in breast cancer survivors. Appl. Physiol. Nutr. Metab. 2014, 39, 730-739. [CrossRef]

41. Hagstrom, A.D.; Marshall, P.W.; Lonsdale, C.; Papalia, S.; Cheema, B.; Toben, C.; Baune, B.T.; Fiatarone Singh, M.A.; Green, S. The effect of resistance training on markers of immune function and inflammation in previously sedentary women recovering from breast cancer: A randomized controlled trial. Breast Cancer Res. Treat. 2016, 155, 471-482. [CrossRef] [PubMed]

42. Hagstrom, A.D.; Shorter, K.A.; Marshall, P.W.M. Changes in Unilateral Upper Limb Muscular Strength and Electromyographic Activity After a 16-Week Strength Training Intervention in Survivors of Breast Cancer. J. Strength Cond. Res. 2019, 33, 225-233. [CrossRef] [PubMed]

43. Hagstrom, A.; Denham, J. The Effect of Resistance Training on Telomere Length in Women Recovering from Breast Cancer. J. Funct. Morphol. Kinesiol. 2018, 3, 9. [CrossRef]

44. Hagstrom, A.D.; Denham, J. microRNAs in High and Low Responders to Resistance Training in Breast Cancer Survivors. Int. J. Sports Med. 2018, 39, 482-489. [CrossRef]

45. Madzima, T.A.; Ormsbee, M.J.; Schleicher, E.A.; Moffatt, R.J.; Panton, L.B. Effects of Resistance Training and Protein Supplementation in Breast Cancer Survivors. Med. Sci. Sports Exerc. 2017, 49, 1283-1292. [CrossRef]

46. Schmitz, K.H.; Troxel, A.B.; Cheville, A.; Grant, L.L.; Bryan, C.J.; Gross, C.R.; Lytle, L.A.; Ahmed, R.L. Physical Activity and Lymphedema (the PAL trial): Assessing the safety of progressive strength training in breast cancer survivors. Contemp. Clin. Trials 2009, 30, 233-245. [CrossRef]

47. Schmitz, K.H.; Ahmed, R.L.; Troxel, A.; Checile, A. Weight lifting in women with breast-cancer-related lymphedema. N. Engl. J. Med 2009, 361, 664-773. [CrossRef]

48. Speck, R.M.; Gross, C.R.; Hormes, J.M.; Ahmed, R.L.; Lytle, L.A.; Hwang, W.-T.; Schmitz, K.H. Changes in the Body Image and Relationship Scale following a one-year strength training trial for breast cancer survivors with or at risk for lymphedema. Breast Cancer Res. Treat. 2010, 121, 421-430. [CrossRef] 
49. Schmitz, K.H.; Ahmed, R.L.; Troxel, A.B.; Cheville, A.; Lewis-Grant, L.; Smith, R.; Bryan, C.J.; Williams-Smith, C.T.; Chittams, J. Weight lifting for women at risk for breast cancer-related lymphedema: A randomized trial. JAMA 2010, 304, 2699-2705. [CrossRef]

50. Hayes, S.C.; Speck, R.M.; Reimet, E.; Stark, A.; Schmitz, K.H. Does the effect of weight lifting on lymphedema following breast cancer differ by diagnostic method: Results from a randomized controlled trial. Breast Cancer Res. Treat. 2011, 130, 227-234. [CrossRef]

51. Brown, J.C.; Troxel, A.B.; Schmitz, K.H. Safety of weightlifting among women with or at risk for breast cancer-related lymphedema: Musculoskeletal injuries and health care use in a weightlifting rehabilitation trial. Oncologist 2012, 17, 1120-1128. [CrossRef]

52. Winters-Stone, K.M.; Laudermilk, M.; Woo, K.; Brown, J.C.; Schmitz, K.H. Influence of weight training on skeletal health of breast cancer survivors with or at risk for breast cancer-related lymphedema. J. Cancer Surviv. 2014, 8, 260-268. [CrossRef]

53. Brown, J.C.; Schmitz, K.H. Weight lifting and appendicular skeletal muscle mass among breast cancer survivors: A randomized controlled trial. Breast Cancer Res. Treat. 2015, 151, 385-392. [CrossRef]

54. Brown, J.C.; Schmitz, K.H. Weight Lifting and Physical Function Among Survivors of Breast Cancer: A Post Hoc Analysis of a Randomized Controlled Trial. J. Clin. Oncol. 2015, 33, 2184-2189. [CrossRef]

55. Buchan, J.; Janda, M.; Box, R.; Schmitz, K.; Hayes, S. A Randomized Trial on the Effect of Exercise Mode on Breast Cancer-Related Lymphedema. Med. Sci. Sports Exerc. 2016, 48, 1866-1874. [CrossRef]

56. Cormie, P.; Pumpa, K.; Galvao, D.A.; Turner, E.; Spry, N.; Saunders, C.; Zissiadis, Y.; Newton, R.U. Is it safe and efficacious for women with lymphedema secondary to breast cancer to lift heavy weights during exercise: A randomised controlled trial. J. Cancer Surviv. 2013, 7, 413-424. [CrossRef]

57. Hasenoehrl, T.; Keilani, M.; Palma, S.; Crevenna, R. Resistance exercise and breast cancer related lymphedema-A systematic review update. Disabil. Rehabil. 2020, 42, 26-35. [CrossRef]

(C) 2020 by the authors. Licensee MDPI, Basel, Switzerland. This article is an open access article distributed under the terms and conditions of the Creative Commons Attribution (CC BY) license (http://creativecommons.org/licenses/by/4.0/). 